\title{
A MOTIVATIONAL MODEL OF LEADERSHIP: PREDICTING LONG-TERM MANAGEMENT SUCCESS FROM TAT MEASURES OF POWER MOTIVATION AND RESPONSIBILITY
}

\author{
David G. Winter* \\ University of Michigan
}

\begin{abstract}
In an AT\&T longitudinal study of managers, managerial success after sixteen years is predicted by "responsible power," which is a combination of TAT-based measures of power motivation and responsibility. These results are consistent with previous theory and research on leadership, and are similar to those obtained with the leadership motive pattern, on the same sample, by McClelland and Boyatzis. The theoretical basis and independently established empirical validity of the new measure of responsibility increases our understanding of how power motivation is channeled into responsible "leadership" behavior instead of exploitative dominance strivings.
\end{abstract}

In a recent review of the literature on leadership, Hollander concluded that, for all of the research that has been done on leadership and the effects of leaders on followers, we have only "a poorly developed picture of the motivational factors that underlie the behavior of individual leaders" (1985, p. 526; see also House \& Singh, 1987, p. 672). In armchair theorizing, leaders are often said to be dirven by the will to power, but Hermann (1986, pp. 175-176) lists several other motives attributed to leaders: commitment to a cause, sense of obligation, need for approval and esteem, challenge of a position, need for status and recognition, and finally compensation for personal problems (see also Bass, 1990).

*Direct all correspondence to: David G. Winter, Department of Psychology, University of Michigan, 580 Union Drive, Ann Arbor, MI 48109-1346

Leadership Quarterly, 2(2), 67-80.

Copyright $\odot 1991$ by JAI Press Inc.

All rights of reproduction in any form reserved.

ISSN: 1048-9843 
Do leaders' motives affect their performance? Does it make a difference whether leaders are motivated by power for other motives? Is the power motive necessarily bad? Can it be "tamed" to produce "good" leadership rather than "bad" domination? How? This article suggests some answers to these questions by reporting results of a secondary analysis of an American Telephone and Telegraph Company (AT\&T) longitudinal study of managers (Howard \& Bray, 1988) over sixteen years, drawing on an earlier study of this same sample by McClelland and Boyatzis (1982).

This study focuses on two particular motives and one other characteristic thought to modify or channel motive effects: (1) the power motive, a concern for impact and prestige, which is associaled with getting formal social power and also profligate impulsive actions such as aggression, drinking, and taking extreme risks (Winter, 1973; Winter \& Stewart, 1978); (b) the affiliation motive, a concern for close relations with others, which predicts interpersonal warmth and communication at least under conditions of low threat or stress (Boyatzis, 1972; McClelland, 1985, chapter 9); and (c) responsibility, a new measure of an old and widely-used concept, which affects the ways in which power motivation is expressed or channeled (Winter \& Barenbaum, 1985). The work of Brown (1965) and Wiggins (1980), among many others, suggests that power and affiliation are the two major dimensions of human social behavior and therefore social motivation. They are drawn from Murray's (1938) comprehensive taxonomy, and are typically measured by content analysis of Thematic Apperception Test (TAT) stories or other verbal material, ${ }^{1}$ as is the new responsibility measure.

\section{POWER MOTIVATION AND LEADERSHIP}

\section{Early Studies}

Although there have been many studies relating achievement motivation to success in entrepreneurial and small business roles, one of the first studies of motivation and leadership performance in executive roles in large organizations was carried out by Cummin (1967), who found that more successful executives scored significantly higher in power motivation than did less successful executives. ${ }^{2}$ (Cummin used a modified version of the original scoring system developed by Veroff, 1957). A similar result was reported by Varga (1975), who found that high power motivation, in combination with high achievement motivation, was associated with technical and economic success in a sample of 110 Hungarian engineer-executives working on research and development projects.

Working with a revised measure, Winter (1973, chapter 4) reported several studies that support a connection between the power motive and leadership success. People scoring high in power motivation make themselves more "visible" and are adept at establishing themselves in influential positions in organizations and developing networks of potential allies. They choose occupations that permit them to direct and sanction the behavior of individual other people. In experimental small groups, they talk a lot and are rated by peers as influential in defining problems and encouraging participation.

Among United States presidents from Washington through Lyndon Johnson, power motivation (measured at a distance from first inaugural) significantly predicted overall 
ratings of "greatness" by historians (Winter, 1987). Using these same scores, House, Spangler, and Woycke (1990) found a significant relationship to presidential "charisma," as well as presidential performance in the international and social policy arenas.

\section{McClelland's “Leadership Motive Pattern"}

Growing out of research on motivational factors in drinking (McClelland, Davis, Kalin, \& Wanner, 1972, chapter 7), McClelland and his colleagues later developed a measure of the "leadership motive pattern." This pattern has three components: (a) power motivation moderate to high (greater than one-half $S D$ below the mean), (b) standardized power motivation greater than standardized affiliation motivation, and (c) activity inhibition ${ }^{3}$ high (typically above the median).

Managers with this motive pattern generate higher morale in their subordinates (McClelland, 1975, pp. 300-301; see also McClelland \& Burnham, 1976). In a study of high-level United States naval officers holding nontechnical jobs, Winter (1978) found that this pattern was associated with "superior" (versus average) ratings by supervisory officers. Among officers with technical jobs, however, no motive variable predicted supervisory ratings.

Nations with the leadership motive pattern spend relatively more for military forces and less for private consumption, which McClelland (1975, p. 308) took as a measure of system capacity to mobilize resources in the (perceived) national interest. In historical studies, the pattern predicts war (McClelland, 1975, chapter 9), as might be expected from the military expenditure finding. Spangler and House (in press) found that the elements of this pattern predicted performance among United States presidents. ${ }^{4}$

\section{AT\&T Longitudinal Study}

The most widely-known study of the leadership motive pattern, by McClelland and Boyatzis (1982), involved a longitudinal study of managers in six Bell telephone companies. In 1956, Douglas Bray initiated a longitudinal study of 422 technical and nontechnical managers who were either directly hired or else promoted into management jobs by age thirty two. All subjects were given a six-picture TAT at an initial three-day assessment center. In a longitudinal follow-up of these men sixteen years later, McClelland and Boyatzis found that the leadership motive pattern was significantly associated with executive or managerial success (reaching levels 3 or above in the AT\&T hierarchy), but only among those people who had nontechnical jobs. No motive variables predicted success for technical managers. Findings for both the nontechnical and technical managers, then, replicated Winter's original findings among naval officers.

A study of managers in a more service-oriented organization, by Cornelius and Lane (1984), produced ambiguous findings. Managers who were located in the higher status branch offices of the organization-arguably one kind of management "success"-were more likely to show the leadership motive pattern. (Since the study was not longitudinal, it is not clear which variable is cause and which is effect.) Overall, however, the leadership motive pattern was negatively associated with a manager's success defined in terms of the performance of that manager's branch office. 


\section{Problems with the Leadership Motive Pattern Measure}

As suggested above, the leadership motive pattern was originally developed on an empirical basis, as a pattern of component motive scores that predicted certain actions and outcomes (originally, low drinking; later, leadership and management success; see McClelland, 1975, pp. 66-67). McClelland and Boyatzis later developed a theoretical rationale to account for the findings as they accumulated.

\footnotetext{
High $\boldsymbol{n}$ Power is important because it means the person is interested in the "influence game," in having impact on others; lower $n$ Affiliation is important because it enables the manager to make difficult decisions without worrying unduly about being liked; and high self-control is important because it means the person is likely to be concerned with maintaining organizational systems and following orderly procedures (1982, p. 737; see also McClelland, 1975, pp. 284-290).
}

Despite this rationale, theoretical and empirical questions can also be raised about some of the components of the leadership motive pattern. For example, are successful leaders really low in the affiliation motive, as suggested by the pattern? Consider the research of Stogdill and his colleagues at Ohio State University, which identified initiating structure (getting people to follow rules and procedures) and consideration (helping, being friendly and available) as the two key dimensions of leader behavior. Although behavior and motivation are conceptually distinct, these two dimensions seem remarkably similar to the power and affiliation motives. A good deal of research suggests that both dimensions of leader behavior are involved in successful leadership, though the exact contribution of each dimension depends on many other variables (see Bass, 1990; Hollander, 1985, pp. 493-495).

Some empirical results obtained with the motive measures support this point. For example, Cummin (1967) found a nonsignificant but positive correlation between the affiliation motive and executive success, and the results of Cornelius and Lane(1984) cited above actually mean that affiliation motivation is positively related to managerial performance. Finally, in a study of leader performance among American presidents, Winter (1987, Table 2) found that subtracting affiliation from power actually lowered the correlations between power motivation and several dependent variables reflecting presidential performance. Thus there are both theoretical and empirical grounds for questioning whether affiliation motive scores should enter the leadership motive pattern as a negative component.

The activity inhibition measure seems to be of uncertain conceptual and theoretical status. It has undoubted predictive validity, but little theoretical rationale or independent empirical construct validity. Many different lines of argument suggest that power must be controlled or tempered; like fire, power has a dual nature: "It can do useful things; it can be fun to play with and to watch; but it must be constantly guarded and trimmed back, lest it burn and destroy" Winter, 1973, p. xviii). By itself, the power motive predicts both responsible "leadership" and profligate, impulsive actions (Winter 1988; Winter \& Stewart, 1978). In management simulation experiments, unmoderated power motivation is related to vulnerability to ingratiation (Fodor \& Farrow, 1979) and "groupthink" or defective decision-making (Fodor \& Smith, 1982). On both theoretical and empirical grounds, then, we presume that power motivation must be channeled or partitioned in some way in order to produce leadership as opposed to 
ineffective power-related actions. The research cited above does suggest that activity inhibition moderates the expression of power motivation. On the other hand, there is little independent evidence or theoretical justification for suggesting that activity inhibition - defined as the frequency of use of the word "not"-is a measure of "selfcontrol," as assumed by McClelland and Boyatzis in the quotation above. ${ }^{5}$ In fact, its roots are strictly empirical, going back to computer-based studies of frequencies of differential word frequencies in folktales of high-drinking versus low-drinking cultures (see McClelland, Davis, Kalin, \& Wanner, 1972, pp. 59ff).

\section{THE CONCEPT OF RESPONSIBILITY}

The present study was designed to establish whether responsibility might be such a moderator variable in the expression of power motivation. Recently Winter and Barenbaum (1985) developed a TAT measure of responsibility that moderated the expression of power motivation into either "responsible" or "profligate" channels. Further studies by Barenbaum (1987), Winter (1989) and Winter and Barenbaum (1989) have extended the construct validity of the responsibility measure, as described below. Will responsibility also moderate the expression of power motivation among people in leadership positions? In this study, responsibility is used in combination with power motivation to predict success in leadership and management. The overall goal is to determine whether the more theoretically-grounded idea of "responsible power" converges with the empirically-derived leadership motive pattern, through another secondary analysis of the AT\&T longitudinal data set.

Responsibility is an important concept in many different domains of human activity, ranging from law to existential philosophy (Sartre, 1946) to executive leadership (Barnard, 1938, chapter 17). People are said to be "responsible" in several different senses: (a) they act on their own initiative and "take" responsibility, (b) they "own" or acknowledge their behavior, (c) they are dependable and can be counted upon, and finally (d) they are responsible for others. While the word "responsibility" is rarely found in personality research studies or textbooks, the underlying concept is clearly reflected in work on political leadership (Weber, 1948/1919, pp. 115-117); moral judgment (Gilligan, 1982) and moral action (Blasi, 1980; 1983); ego control (J. H. Block \& J. Block, 1980) or impulse control (Pulkkinen, 1986); prosocial-versus-antisocial behavior (Olweus, Block, \& Radke-Yarrow, 1986); delay of gratification (Mischel, 1974; 1986, chapter 17); and even the Socialization Scale of the California Psychological Inventory, among many other topics.

The TAT-based measure of responsibility was developed by Winter and Barenbaum (1985) to bring together all of these different aspects of "responsible" behavior in a single concept that could then be systematically studied. (This measure is further described in the next selection.) Winter and Barenbaum found that among several different groups of women and men scoring high in responsibility, the power motive predicted leadership and effective functioning; for example, holding a power-related job, being a member of organizations, and seeing one's self as a "responsible person" in the eyes of others. Among women and men low in responsibility, however, power motivation was associated with "profligate, expansive impulsivity;" for example, drinking, verbal and physical aggression, and sexual acting out. 
Barenbaum (1987) also used this responsibility measure as a moderator of power motivation in a study of mothers who were in the proccss of separation and divorce. Among divorcing mothers high in responsibility, power motivation was associated with better management of conflict with former spouse, while among divorcing mothers low in responsibility, power motivation was related to open expression of conflict (blaming former spouse, verbal aggression and litigation, and involving children in the conflicts with former spouse).

Winter and Barenbaum (1989) carried out a secondary analysis of "prosocial" and "antisocial aggression" data from the longitudinal study of children whose mothers had originally been interviewed as a part of the Sears, Maccoby, and Levin Patterns of Childrearing study (1957), and who themselves wrote Thematic Apperception Test stories at age thirty. As defined by Sears (1961), prosocial aggression is "aggression used in a socially approved way for purposes that are acceptable to the moral standards of the group," with "appropriate rules about aggression" and "socially acceptable controls and disciplines" (p. 471). The following is an example of the eight component items: "When a person has broken an important rule, he should definitely be punished for it." Antisocial aggression involves acts or sentiments "that are normally unacceptable socially in the formal pattern of our culture" (p. 471), as reflected in the following example of the nine component items: "Sometimes an actual fight is the only way to settle an argument." Among those children who later scored high in responsibility, power motivation correlated positively with prosocial aggression and negatively with antisocial aggression. Where later responsibility was low, the correlations reversed.

Finally, in a secondary analysis of data from the longitudinal Grant study of male Harvard graduates from the classes of 1939-1943, Winter (1989) found that the responsibility measure by itself predicted subsequent career and family adaptation.

\section{MEASURING RESPONSIBILITY IN TATS}

In a review of research on power motivation in men and women, Winter (1988) showed that growing up with younger siblings and/or having children in adulthood-two variables assumed to reflect the experience of having responsibility-both moderated the expression of power motivation into either "responsible" or "profligate" channels. Winter and Barenbaum (1985) developed a direct Thematic Apperception Test (TAT) measure of responsibility by comparing TATs of a small group of five male college students who scored high in power motivation and who had younger siblings and who had children by the time they were thirty two, with TATs from another small group of five male college students scoring high in power motivation who did not have younger siblings and who had not had children by the time they were thirty two. They then cross-validated this preliminary scoring system on two further samples: (1) groups of new fathers (presumed to have an aroused sense of responsibility) and students with younger siblings (total $N=16$ ) versus groups of men (without children) beginning entry-level jobs and students without younger siblings (total $N=16$ ); and (2) a sample of 156 college students retrospectively reporting high versus low parental expectations for doing chores and other responsible behaviors during ages 6-13. 
The final version of the responsibility TAT scoring system consists of the following five categories, each scored as "present" (scored +1 ) or "absent" (scored 0 ) in each story. The overall score is the sum of points scored for all stories. ${ }^{6}$

1. Moral-legal standard. Actions, people, or things explicitly described in terms of some abstract standard involving either morality ("right/wrong") or legality ("legal/illegal").

2. Obligation. Character in the story is obliged to act because of an inner feeling of compulsion or impersonal rule, regulation, or instruction.

3. Concern for others. Character helps another or shows sympathetic concern.

4. Concern about consequences. Character is concerned about or reflects on possible negative consequences of actions.

5. Self-judgment. Characters critically evaluate their own character, wisdom, selfcontrol, or good sense.

\section{RATIONALE AND HYPOTHESES OF THE PRESENT STUDY}

The present study was designed for three principal purposes: (a) to test the generality of the Winter and Barenbaum (1985) and Barenbaum (1987) findings about the moderating effects of responsibility on power motivation; (b) specifically, to determine whether power motivation as moderated by responsibility predicts leadership and management success among people with nontechnical jobs in the same way as the leadership motive pattern does; and (c) thereby to explore the classic ideas of Barnard (1938, chapter 17), among others, who stressed the role of responsibility in executive leadership.

\section{SUBJECTS AND METHODS}

In 1956, Douglas Bray initiated a longitudinal study of 422 tcchnical and nontechnical managers in six telephone companies formerly part of the Bell System: 274 newly hired male college graduates and 148 non-graduates who had advanced into management jobs by age thirty-two. Of these, 355 wrote stories to six TAT cards (7BM, 6BM, 8BM, 2 , and 16) at an initial three-day assessment center. (See Howard \& Bray, 1988, for a complete discussion of this longitudinal study.) These stories had been scored for power and affiliation motives by McClelland and Boyatzis (1982). TAT protocols from those 244 men still with the company sixteen years later were made available for the present research, along with information about the level of management attained sixteen years after assessment, as well as type of job (technical-construction, installation or repair of equipment, $N=103$; and nontechnical-services, marketing, administration and personnel, $N=141$ ). In line with the previous results of McClelland and Boyatzis (1982) and Winter (1978), predictions of managerial success will only be made for men in nontechnical jobs; success in technical jobs appears to involve specific technical skills more than personality dispositions.' (The total sample will be used, however, to explore relationships among the different TAT-based variables.)

For the present study, the original TATs were scored for responsibility by trained scorers who had previously demonstrated high reliability (category agreement $=85$ 
Table 1

\section{Longitudinal Managerial Success in Relation to Responsible Power and Leadership Motive Pattern}

\begin{tabular}{|c|c|c|c|}
\hline \multirow[b]{2}{*}{ Pattern of TAT-based variables } & \multicolumn{3}{|c|}{$\begin{array}{c}\text { Percent at management level } 3 \text { (or higher) } \\
16 \text { years after assessment }\end{array}$} \\
\hline & $\begin{array}{l}\text { Pattern } \\
\text { present }\end{array}$ & $\begin{array}{c}\text { Pattern } \\
\text { not present }\end{array}$ & $\begin{array}{c}\text { Significance } \\
\text { of difference } \\
\text { in percents }\end{array}$ \\
\hline \multirow{4}{*}{$\begin{array}{l}\text { Responsible power } \\
\text { Leadership motive pattern }^{\mathrm{b}} \\
\text { Responsibility high and } \\
\quad \text { power-minus-affiliation } \\
\text { c also high }\end{array}$} & 77 & 56 & $\chi^{2}=5.42, p<.02$ \\
\hline & 79 & 57 & $\chi^{2}=5.77, p<.02$ \\
\hline & & & \\
\hline & 76 & 55 & $\chi^{2}=7.65, p<.01$ \\
\hline \multicolumn{4}{|c|}{ 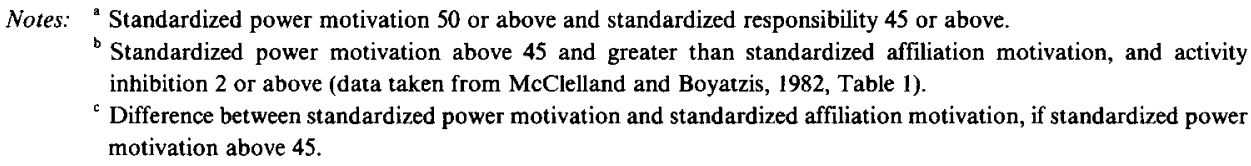 } \\
\hline
\end{tabular}

percent or better) with expert scoring of practice materials, and who were blind to the hypotheses of the research and any other information about the subjects. Raw responsibility scores were significantly correlated with the length of the total TAT protocol $(r=.42, p<.001)$. To remove the effects of this correlation, the score for each subject that would be predicted by the regression of responsibility on protocol length was subtracted from that subject's raw score (see Winter, 1973, p. 146). Corrected responsibility scores were then divided into high and low (dividing point of half a standard deviation below the mean ${ }^{8}$ ) and combined with power motive scores (divided at the mean) to define a group of subjects high in power motivation and moderate to high in responsibility - those with "responsible power"-versus the rest of the sample. This dichotomous variable was constructed to be as closely analogous as possible to the leadership motive pattern measure, and was predicted to relate to the 16-year follow-up measure of management level among managers with nontechnical jobs.

Some important limits of the present study should be recognized. There are undoubtedly many different criteria for "leadership" or "leadership success," and we have no reason to believe that such alternative criteria are highly intercorrelated. Among U.S. presidents, for example, Winter (1987) used two different (and unrelated) measures of leadership success - electoral margin of victory and historians' ratings of greatnessand found different motive-profile correlates for each measurc. In the prescnt study, leadership was operationally defined only in terms of advancement in the AT\&T hierarchy. An "objective" measure of managerial performance, if one that was comparable across all the different jobs represented in the present sample were available, might yield different results, as suggested by the Cornelius and Lane (1984) pattern of results mentioned above. (In "well-run" organizations, of course, these two measures ought to converge over time.) 


\section{RESULTS}

\section{Predicting Managerial Success}

The results, shown in Table 1, are as expected. Among the 43 men with "responsible power" (scoring high in both power motivation and moderate to high in responsibility), 33 ( 77 percent) were at level 3 or higher sixteen years later; while among the 98 men with other motive patterns, only 55 (56 percent) had attained this level (Chi-square = $5.42, p<.02)$. The effect is of almost exactly the same magnitude as that reported by McClelland and Boyatzis (1982) for the leadership motive pattern (also shown in Table 1 for comparison). Moreover, the results are the same if responsibility is combined with power-minus-affiliation score (divided at the mean), as shown at the bottom of the table.

\section{Responsibility and the Leadership Motive Pattern}

The results reported in Table 1 suggest that the two different ways of dividing up or "partitioning" the power motive, though of different theoretical origins, are empirically equivalent in terms of predicting leadership and managerial success as defined by managerial level attained after sixteen years at AT\&T. More broadly: in terms of their overall moderating or "channeling" effect on power motivation, responsibility plays a role similar to that of the "other" components of the leadership motive pattern (low affiliation motivation and high activity inhibition). Consistent with this conclusion, the behaviors of people high in power motivation and low in responsibility, as reported by Winter and Barenbaum (1985), are similar to those of people studied by McClelland who have the "conquistador" motive pattern, which consists of high power motivation which is also greater than affiliation motivation, but with low activity inhibition (see McClelland, 1975, pp. 295-299; 1985, pp. 308-311), including specifically drinking, anger, and sexual exploitation.

If responsibility and the leadership motive pattern components are in many respects empirically equivalent, are they really the same? There are grounds for imagining that they are. As implied in the conceptual discussion above, responsibility often has the connotation of "restraint" or "control," particularly when applied to a "dual-nature"

Table 2

Relationship of Responsible Power to the Leadership Motive Pattern

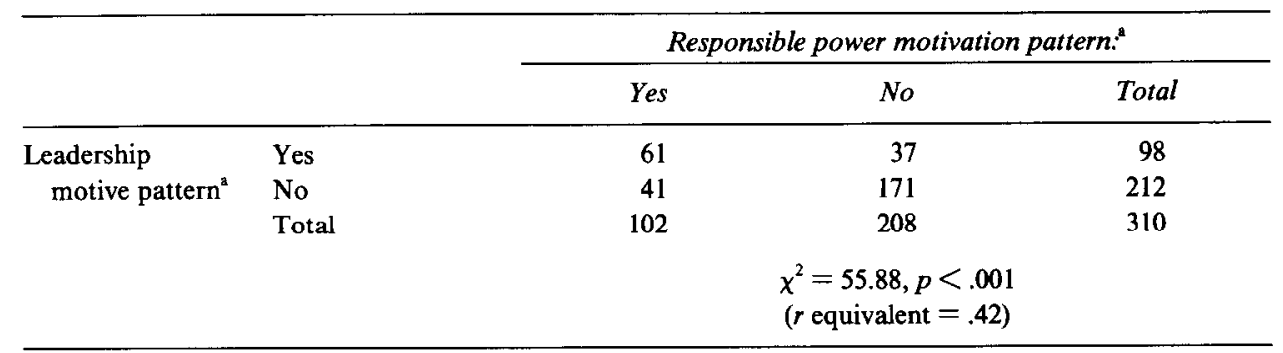

\footnotetext{
${ }^{a}$ See Notes $a$ and $b$ of Table 1 for definitions.
} 
Table 3

Relationship of Responsibility to Leadership Motive Pattern Components

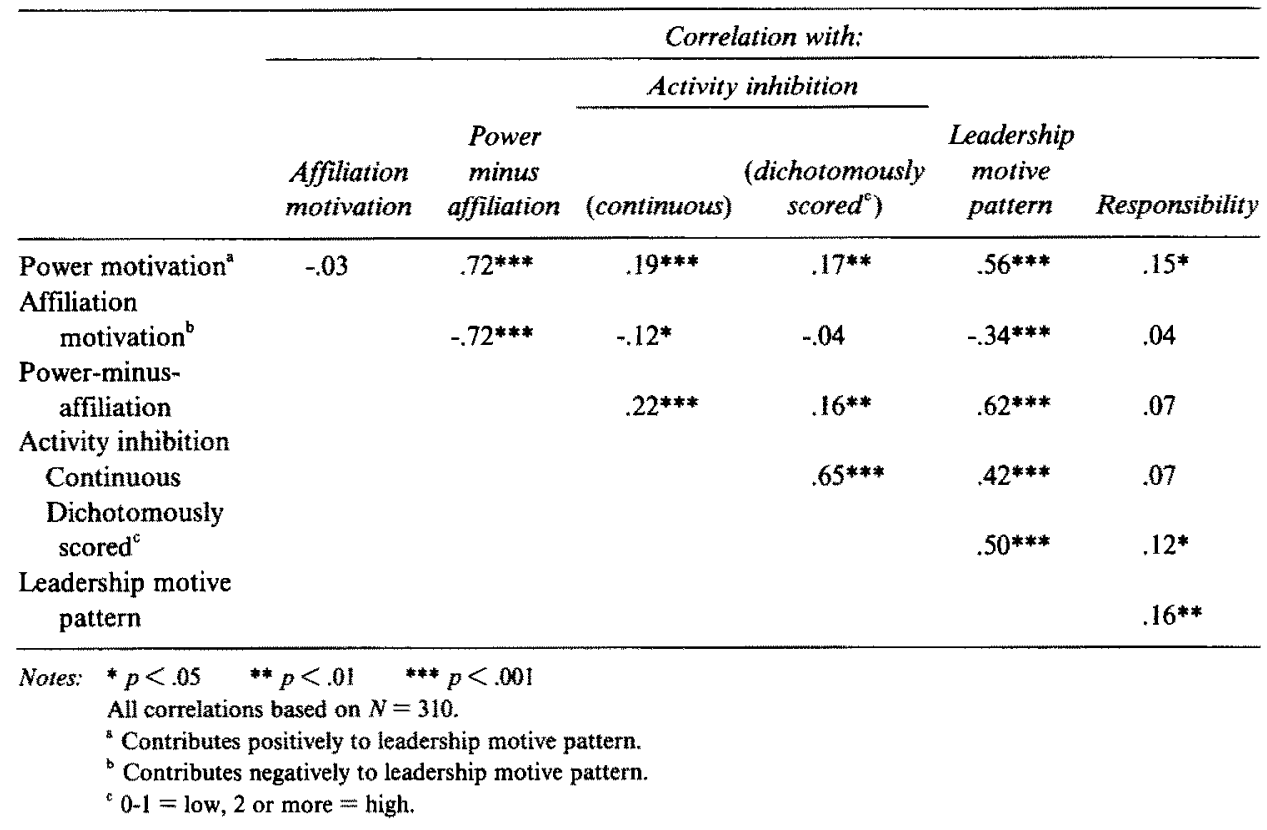

motive such as power. And as shown in Table 2, the "responsible power" combination is significantly related to the leadership motive pattern ( $r$ equivalent of Chi-square $=$ .42). The average responsibility score for the 98 men with the leadership motive pattern is significantly greater than the average for the 212 men with all other combinations of power and affiliation motives and activity inhibition (means $=52.37$ and 48.90 , respectively, $t=2.87, p<.01$ ), but the magnitude of this difference has little practical or theoretical significance.

Table 3 presents the intercorrclatons of responsibility and all of the components of the leadership motive pattern. The correlations involving responsibility suggest that it has small but significant relationships to power motivation and dichotimized activity inhibition, but is essentially unrelated to the other components. Again, even the statistically significant correlation coefficients are of little practical significance, because they indicate only a small amount of shared variance. Thus we may conclude that although responsibility tempers power in ways similar to the "other" components of the leadership motive pattern, it does not have much empirical overlap with any of these other components.

\section{SUMMARY}

In simplest terms, the results of the present study suggest that "responsible power"high power motivation and high responsibility-predicts success in corporate management over a time-span of sixteen years. The responsible power motive pattern 
is at least as successful as the leadership motive pattern, while avoiding some of the theoretical and epistemological problems associated with that pattern (specifically taking the frequency of occurence of the word "not" as a measure of activity inhibition).

This result is quite consistent with much of the literature on managerial or executive leadership (see Barnard, 1938; Bass, 1990; Hermann, 1986; Hollander, 1985; Levinson \& Rosenthal, 1984; and Winter, 1978). Successful leaders and managers must use power-to influence others, to monitor results, and to sanction performance; but this power must be exercised in "responsible" ways that involve ethical standards, accountability for consequences, and a concern for effects on subordinates and peers. Each of thcsc restraints on the exercise of power is closely analogous to one or more categories of the responsibility scoring system.

In terms of further validation of the responsibility measure and its role in moderating the power motive, these results converge with those reported by Winter and Barenbaum (1985, 1989) and Barenbaum (1987). Among people scoring high in responsibility, the power motive predicts "responsible" forms of power-use (including aggression only when restrained by standards and controls). Among people scoring low in responsibility, power motivation predicts unrestrained aggressive impulses. "Responsible power," then, is power tempered by moral and legal standards, by a concern for consequences or the welfare of others, and by a sense of obligation and self-judgment. This responsibility measure may be useful in future research on leadership and other kinds of controlled (versus uncontrolled) expressions of power. ${ }^{9}$

The present results need to be taken with caution: they suggest only one motivational model of leadership, and that in a particular hierarchical organization. As Winter's (1987) study of presidential leadership demonstrates, using alternative criteria of leadership success might reveal other models.

In terms of our understanding of the leadership process, the present results echo the advice of Max Weber (1948/1919), first given over seventy years ago.

\footnotetext{
One can say that three pre-eminent qualities are decisive for the [leader]: passion, a feeling of responsibility, and a sense of proportion.... To be sure, mere passion, however genuinely felt, is not enough. It does not make a [leader], unless passion as devotion to a "cause" also makes responsibility to this cause the guiding star of action. And for this, a sense of proportion is needed.... [The leader] works with the striving for power as an unavoidable means. Therefore, "power instinct," as is usually said, belongs indeed to his normal qualities. The sin against the lofty spirit of his vocation, however, begins where this striving for power ceases to be objective and becomes purely personal self-intoxication, instead of exclusively entering the service of "the cause." (pp. 115-116)
}

\section{ACKNOWLEDGMENTS}

The research reported in this paper was supported by grants from the Corporate Council on the Liberal Arts and from the Henry A. Murray Research Center of Radcliffe College.

For the use of data from the AT\&T longitudinal study, I am grateful to Ann Howard and David C. McClelland. I am also grateful to Kristin McClenahan and Nicole Barenbaum for scoring the TAT protocols for responsibility, to Abigail Stewart for critical discussion of the analysis and results, and to Robert House for comments and suggestions on an earlier draft. Naturally, the responsibility for all conclusions and opinions is mine. 


\section{NOTES}

1. A full discussion of the psychometric characteristics and construct validity of the TAT motive measures (including issues of reliability) can be found in the sources indicated, as well as in Lundy (1985), McClelland (1980), Weinberger and McClelland (1990), Winter (1991), and Winter and Stewart (1977).

2. Cummin also found a significant relationship between achievement motivation and success.

3. Activity inhibition is usually defined as the frequency of use of the word "not," although House and his colleagues (House, Spangler, \& Woycke, 1990; Spangler \& House, in press) have modified this procedure slightly when the "not" measure was not feasible.

4. The results of Spangler and House (in press) suggest that the predictive power of the leadership motive pattern may lie in its components and their interactions, rather than in the dichotomously-defined "syndrome."

5. Although not cited by McClelland and Boyatzis, Freud described negations as "intellectual acceptance of the repressed, while at the same time what is essential to the repression persists" (1961/1925, p. 236), and also a component of the "postponing activity of thought" $(1964 / 1933$, p. 89n).

6. This brief outline is not adequate for scoring purposes. The complete scoring manual, along with learning instructions and practice materials, is available at cost from the author.

7. The nontechnical and technical managers did not differ in initial levels on any TAT-based variable. TAT's were not available for managers who had left AT\&T before the follow-up. They were more likely to have been college graduates originally, but it is difficult to see how this difference could bias or otherwise affect the generalizability of the present results.

8. This level was used, rather than the mean or median, to increase the number of cases with high responsibility scores.

9. Scoring materials are available as described in Note 6 .

\section{REFERENCES}

Barenbaum, N. B. (1987). Power motivation, responsibility, and conflict among divorcing parents. Unpublished doctoral dissertation, Boston University.

Barnard, C. (1938). The functions of the executive. Cambridge, MA: Harvard University Press.

Bass, B. M. (1990). Bass and Stogdill's handbook of leadership: Theory, research, and managerial applications (3rd ed.). New York: Free Press.

Blasi, A. (1980). Bridging moral cognition and moral action: A critical review of the literature. Psychological Bulletin 88, 1-45.

Blasi, A. (1983). Moral cognition and moral action: A theoretical perspective. Developmental Review 3, 178-210.

Block, J. H. \& J. Block (1980). The role of ego-control and ego-resiliency in the organization of behavior. In W. A. Collins (Ed.), Minnesota symposium on child psychology (Vol. 13). New York: Erlbaum.

Boyatzis, R. E. (1973). Affiliation motivation. In D. C. McClelland \& R. S. Steele (Eds.), Human motivation (pp. 252-276). Morristown, NJ: General Learning Press.

Brown, R. W. (1965). Social psychology. New York: Free Press.

Cornelius, E. T. \& F. B. Lane (1984). The power motive and managerial success in a professionally oriented service industry organization. Journal of Applied Psychology 69, 32-39.

Cummin, P. C. (1967). TAT correlates of executive performance. Journal of Applied Psychology $51,78-81$.

Fodor, E. M. \& D. L. Farrow. (1979). The power motive as an influence on the use of power. Journal of Personality and Social Psychology 37, 2091-2097. 
Fodor, E. M. \& T. Smith (1982). The power motive as an influence on group decision making. Journal of Personality and Social Psychology 42, 178-185.

Freud, S. (1961). Negation. In Standard edition of the complete psychological works of Sigmund Freud (Vol. 19, pp. 233-239). London: Hogarth Press. (Originally published 1925)

Freud, S. (1964). Anxiety and instinctual life. Lecture 32 in New introductory lectures on psychoanalysis. In Standard edition of the complete psychological works of Sigmund Freud (Vol. 22, pp. 1-182). London: Hogarth Press. (Originally published 1933)

Gilligan, C. (1982). In a different voice. Cambrige, MA: Harvard University Press.

Hermann, M. G. (1986). Ingredients of leadership. In M. G. Hermann (Ed.), Political psychology: Contemporary issues and problems (pp. 167-192). San Francisco: Jossey-Bass.

Hollander, E. P. (1985). Leadership and power. In E. Aronson \& G. Lindzey (Eds.), Handbook of social psychology, 3rd edition (Vol. 2, pp. 485-537). New York: Random House.

House, R. J. \& J. V. Singh (1987). Organizational behavior: Some new directions for I/O psychology. In Annual review of psychology (Vol. 38, pp. 669-718). Palto Alto, CA: Annual Reviews.

House, R. J., W. D. Spangler, \& J. Woycke. (1990). Personality and charisma in the U.S. Presidency: A psychological theory of leader effectiveness. Unpublished paper, University of Pennsylvania.

Howard, A. \& D. Bray. (1988). Managerial lives in transition: Advancing age and changing times. New York: Guilford.

Levinson, H. \& S. Rosenthal. (1984). CEO: Corporate leadership in action. New York: Basic Books.

Lundy, A. (1985). The reliability of the Thematic Apperception Test. Journal of Personality Assessment 49, 141-145.

McClelland, D. C. (1975). Power: The inner experience. New York: Irvington.

McClelland, D. C. (1980). The merits of operant and respondent measures. In L. Wheeler (Ed.), Review of personality and social psychology (Vol. 1, pp. 10-41). Beverly Hills, CA: Sage.

McClelland, D. C. (1985). Human motivation. Glenview, IL: Scott, Foresman.

McClelland, D. C. \& D. Burnham (1976, March-April). Power is the great motivator. Harvard Business Review, 100-110, 159-166.

McClelland, D. C. \& R. E. Boyatzis (1982), Leadership motive pattern and long-term success in management. Journal of Applied Psychology 67, 737-743.

McClelland, D. C, W. N. Davis, R. Kalin, \& E. Wanner (1972). The drinking man. New York: Free Press.

Mischel, W. (1974). Processes in delay of gratification. In L. Berkowitz (Ed.), Advances in experimental social psychology (Vol. 7). New York: Academic Press.

Mischel, W. (1986). Introduction to personality (4th ed.). New York: Holt, Rinehart \& Winston.

Murray, H. A. (1938). Explorations in personality. New York: Oxford University Press.

Olweus, D., J. Block, \& M. Radke-Yarrow (1986). Development of antisocial and prosocial behavior. Orlando, FL: Academic Press.

Pulkkinen, L. (1986). The role of impulse control in the development of antisocial and prosocial behavior. In D. Olweus, J. Block \& M. Radke-Yarrow (Eds.), Development of antisocial and prosocial behavior (pp. 149-175). Orlando, FL: Academic Press.

Sartre, J. P. (1946). Existentialism. New York: Philosophical Library.

Sears, R. R., E. E. Maccoby, \& H. Levin (1957). Patterns of childrearing. Evanston, IL: Row, Peterson.

Sears, R. R. (1961). Relation of early socialization experiences to aggression in middle childhood. Journal of Abnormal and Social Psychology 63, 466-492.

Spangler, W. D. \& R. J. House (In press). Presidential effectiveness and the leadership motive profile. Journal of Personality and Social Psychology. 
Varga, K. (1975). N Achievement, $\mathrm{n}$ power and effectiveness of research development. Human Relations 28, 571-590.

Veroff, J. (1957). Development and validation of a projective measure of power motivation. Journal of Abnormal and Social Psychology 54, 1-8.

Wcber, M. (1948). Politics as a vocation. In H. Gerth \& C. W. Mills (Eds.), From Max Weber: Essays in sociology. London: Routledge \& Kegan Paul. (Originally published 1919)

Weinberger, J. \& D. C. McClelland (1990). Cognitive versus traditional motivational models: Irreconcilable or complementary? In E. T. Higgins \& R. M. Sorrentino (Eds.), Handbook of motivation and cognition (Vol. 2, pp. 562-597). New York: Guilford.

Wiggins, J. S. (1980). Circumplex models of interpersonal behavior. In L. Wheeler (Ed.), Review of Personality and Social Psychology (Vol. 1, pp. 265-294). Beverly Hills, CA: Sage.

Winter, D. G. (1973). The power motive. New York: Free Press.

Winter, D. G. (1978). Navy leadership and managment competencies: Convergence among tests, interviews, and performance ratings. Boston: McBer and Company.

Winter, D. G. (1987). Leader appeal, leader performance, and the motive profiles of leaders and followers: An exploratory study of U.S. presidents and elections. Journal of Personality and Social Psychology 52, 196-202.

Winter, D. G. (1988). The power motive in women-and men. Journal of Personality and Social Psychology 54, 510-519.

Winter, D. G. (1989). Predicting aspects of adult men's adaptation from a TAT-based measure of responsibility. Unpublished paper, University of Michigan.

Winter, D. G. (1991). Measuring personality at a distance: Development of an integrated system for scoring motives in running text. In A. J. Stewart, J. M. Healy, Jr. \& D. Ozer (Eds.), Perspectives in personality: Approaches to understanding lives London: Jessica Kingsley Publishers.

Winter, D. G. \& N. B. Barenbaum. (1985). Responsibility and the power motive in women and men. Journal of Personality 53, 335-355.

Winter, D. G. \& N. B. Barenbaum. (1989). Some childhood and adolescent antecedents of responsibility and responsible power. Unpublished paper, University of Michigan.

Winter, D. G. \& A. J. Stewart, (1977). Power motive reliability as a function of retest instructions. Journal of Consulting and Clinical Psychology 45, 436-440.

Winter, D. G. \& A. J. Stewart (1978). The power motive. In H. London \& J. Exner (Eds.), Dimensions of Personality (pp. 391-447). New York: Wiley. 